\title{
Produção de biomassa microalgal em escala: desafios e oportunidades
}

Beatriz Santos, Diego de Oliveira Corrêa, Nelson Fernando Herculano Selesu, Vanessa Merlo Kava, André Bellin Mariano, José Viriato Coelho Vargas

https://doi.org/10.4322/mp.978-65-994457-8-1.c1

\section{Resumo}

O interesse em novas tecnologias que viabilizem a produção de biomassa de microalgas tem ganhado espaço no meio acadêmico e industrial, sobretudo devido às inúmeras possibilidades de exploração dessa matéria prima. O reflexo da crescente atenção direcionada às microalgas é o surgimento de um novo nicho biotecnológico, que tem como um dos principais desafios o escalonamento da produção de biomassa, ao mesmo tempo em que amplia as possibilidades de exploração desses microrganismos. Dentre os principais desafios encontrados na produção de microalgas em larga escala é possível destacar os custos de desenvolvimento, construção e operação de fotobiorreatores; o volume de água empregada nos cultivos; o suprimento de aeração com ou sem suplementação de $\mathrm{CO}_{2}$; a formulação de meio de cultura com todos os nutrientes necessários; e os processos de recuperação da biomassa produzida. Associadas aos desafios do escalonamento, surgem oportunidades de novos processos a serem explorados, como o tratamento de emissões e efluentes, que permitem a redução dos custos associados ao consumo de água e suplementação do meio com fontes de carbono e outros nutrientes. Entender esses desafios e oportunidades permite delinear estratégias mais efetivas para produção de biomassa microalgal em escala industrial. Neste capítulo, apresenta-se brevemente uma revisão sobre os principais desafios e oportunidades encontrados nos cultivos de microalgas em larga escala.

Palavras-chave: Biomassa, efluentes, emissões, escalonamento, fotobiorreatores, microalgas. 


\section{Introdução}

O interesse em novas tecnologias que viabilizem a produção de biomassa de microalgas tem ganhado espaço no meio acadêmico e industrial na última década, sobretudo devido às inúmeras possibilidades de exploração dessa matéria-prima, quer seja para geração de biocombustíveis como o biodiesel, o etanol ou mesmo o hidrogênio, ou ainda pela composição da biomassa rica em proteínas, pigmentos e moléculas de interesse para as áreas de nutrição humana, suplementação animal e variados usos biotecnológicos. Além de sua utilização para fins comerciais, os cultivos de microalgas são reconhecidos como importantes ferramentas para o estudo de diversos fenômenos ecológicos, fisiológicos, bioquímicos e genéticos, sendo fundamentais para obtenção de informação relacionada à ciência básica e estudo destes microrganismos (HLAVOVA; TUROCZY; BISOVA, 2015).

Pesquisas com microalgas têm sido desenvolvidas para diferentes aplicações comerciais. Como microrganismos fotossintetizantes, as microalgas contêm pigmentos que podem ser usados para fins alimentares e cosméticos, podem ainda ser usadas na indústria farmacêutica, uma vez que algumas espécies produzem compostos bioativos, tais como os antioxidantes. Além disso, a biomassa das microalgas é empregada como suplemento nutricional para o consumo humano, devido à presença de proteínas, vitaminas, polissacarídeos, ácidos graxos poli-insaturados dentre outros nutrientes (DOLGANYUK et al., 2020).

O reflexo da crescente atenção direcionada às microalgas é o surgimento de um novo nicho tecnológico que possui, como uma das maiores potencialidades a ser explorada, a possibilidade de integração entre sistemas de cultivo para produção de biomassa e o tratamento de emissões diversas, com a principal vantagem de aumentar a produtividade dos sistemas, aliada ao aspecto ambiental da redução de poluentes na atmosfera, como o dióxido de carbono $\left(\mathrm{CO}_{2}\right)$ e os óxidos de nitrogênio (NOx). Como seres fotossintetizantes, as microalgas possuem a capacidade de converter biologicamente o $\mathrm{CO}_{2}$ presente em emissões diversas em biomassa, apresentando como resultado desse processo a produção de oxigênio (O2) (MEHARIYA et al., 2021).

Apesar do desenvolvimento de novas tecnologias para produção de biomassa de microalgas os cultivos ainda esbarram em limitações tecnológicas, 
especialmente relacionadas à manutenção e viabilidade das condições da cultura. A interação entre fatores físicos, químicos e biológicos influencia diretamente no cultivo de microalgas, podendo promover ou inibir seu crescimento. Os fatores biológicos estão associados ao metabolismo celular e a presença de contaminantes no sistema, enquanto os fatores físicos e químicos estão relacionados aos efeitos provocados pela luz, temperatura, $\mathrm{pH}$ e disponibilidade de fontes de carbono e outros nutrientes (MORENO-GARCIA et al., 2017).

Compreender as especificidades dos cultivos de microalgas em larga escala permite contornar os desafios e identificar as oportunidades dessa tecnologia, tais como o uso da biomassa para obtenção de bioprodutos e a integração de diferentes processos dentro do conceito de biorrefinaria. O objetivo deste capítulo é trazer as principais atualizações da literatura sobre cultivos em larga escala, bem como a importância da biorrefinaria que permite associar a alta produtividade de compostos de interesse comercial com o tratamento de emissões e efluentes.

\section{Sistemas de cultivo de microalgas em larga escala}

Os cultivos de microalgas são comumente realizados de duas maneiras: sistemas abertos, tais como tanques ou lagoas, ou ainda em sistemas fechados como fotobiorreatores (ASSUNÇÃO e MALCATA, 2020). De modo geral, a utilização de fotobiorreatores para o cultivo de microalgas possui algumas vantagens, dentre as quais é possível destacar o maior controle das condições, uma vez que o sistema é fechado e não há contato com o ambiente externo, reduzindo a probabilidade de contaminação por organismos diferentes dos cultivados e a redução da perda excessiva por evaporação, o que é agravado em dias quentes e secos nos cultivos abertos (XIAOGANG et al., 2020). Fotobiorreatores possuem ainda elevada eficiência na produção de biomassa quando utilizada injeção de $\mathrm{CO}_{2}$ no meio, potencializando a multiplicação celular. O avanço da produção industrial associada com exploração do potencial das microalgas passa pelo desenvolvimento de sistemas de cultivo que sejam capazes reunir estas características. Ademais, a necessidade de desenvolvimento também se faz presente no setor acadêmico, uma vez que o aprimoramento de sistemas de cultivo em larga escala permite a realização de 
estudos que aproximem a realidade da bancada com a industrial, favorecendo assim o escalonamento dos processos investigados.

Tanques abertos que simulam o habitat natural das microalgas são os mais utilizados devido ao baixo custo de construção e manutenção. Três principais modelos têm sido usados na produção em larga escala, os tanques de corrida, as lagoas circulares e os tanques inclinados (BOROWITZKA, 1999). O gasto com a construção dos tanques de corrida é relativamente baixo, já que o sistema consiste numa vala rasa escavada no chão revestido com plástico, sendo que a agitação é promovida por longas pás (Figura 1). O nível da água deve estar entre $15 \mathrm{~cm}$ e $50 \mathrm{~cm}$, valores inferiores ou superiores podem prejudicar o fluxo e diminuir a turbulência. Nesse sistema, o baixo nível de água requer grandes áreas para cultivo, com cerca de $150 \mathrm{~L} \mathrm{~m}^{-2}$, além disso a concentração celular dificilmente ultrapassa $600 \mathrm{mg} \mathrm{L}^{-1}$, facilitando contaminações e aumentando o custo de coleta da biomassa. Outro problema é a perda excessiva por evaporação, que é agravada em dias quentes e secos (TREDICI, 2004).

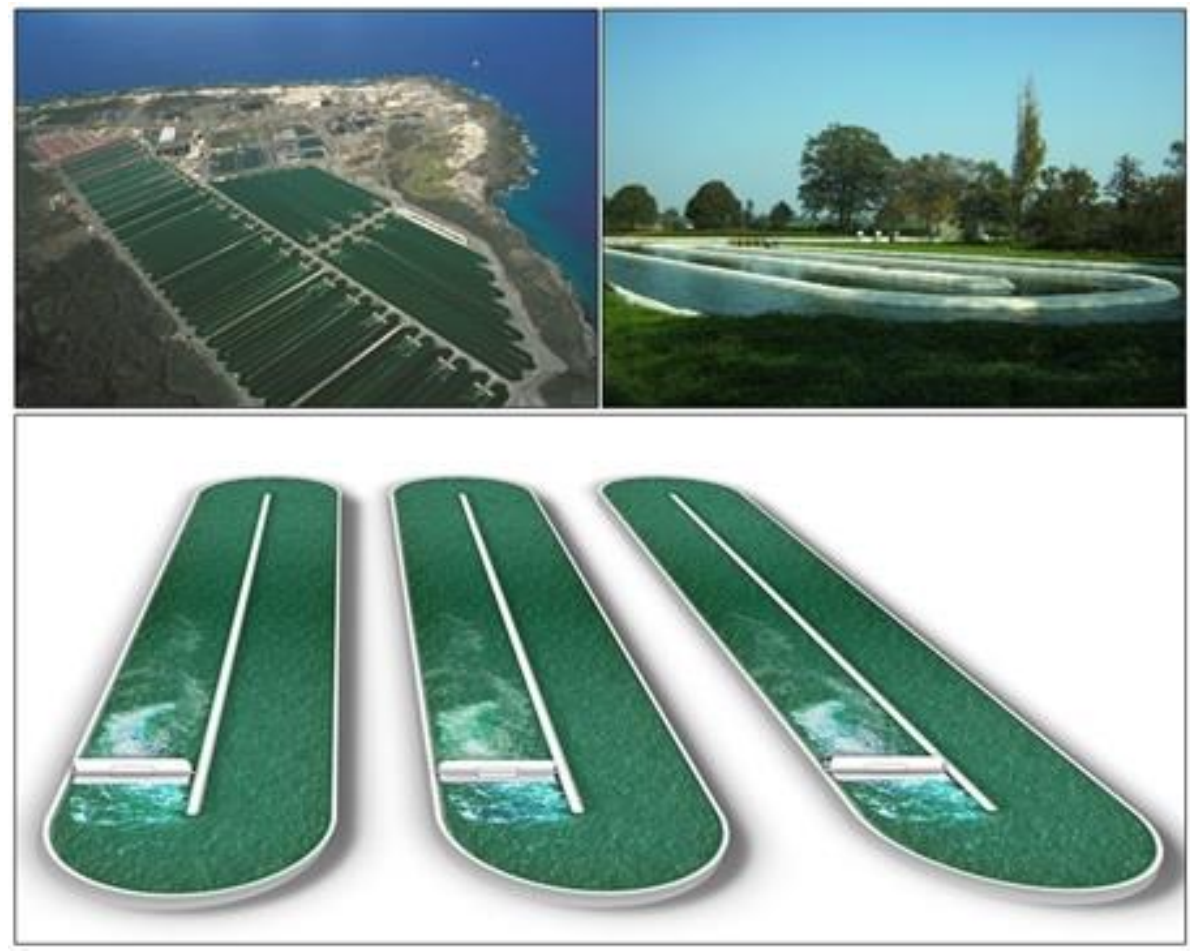

Figura 1. Sistemas abertos para cultivo de microalgas. Fonte: Imagem superior esquerda: Cyanotech Corp. https://upload.wikimedia.org/wikipedia/commons/1/18/AerialCyanotechW.jpg. Imagem superior direita: JanB46. https://upload.wikimedia.org/wikipedia/commons/8/8a/ Microalgenkwekerij te Heure bii Borculo.jpg. Imagem inferior: Ivan Castilho. https://upload.wikimedia.org/wikipedia/commons/5/5a/Algal open pond design.jpg. 
Os sistemas abertos também podem ser definidos como fotobiorreatores, uma vez que são reatores em que organismos fotossintetizantes crescem e realizam suas reações biológicas, no entanto, o termo fotobiorreator é comumente empregado para designar os sistemas fechados. Estes podem ser definidos como sistemas de cultura para organismos autotróficos, no qual a luz incide indiretamente sobre a superfície da cultura, passando previamente através de uma superfície translucida. Sendo assim, fotobiorreatores limitam a troca direta de gases com o meio externo, reduzindo contaminações entre o cultivo celular e a atmosfera (TREDICI, 2004). Além disso, fotobiorreatores ocupam uma área muito menor quando comparados aos sistemas abertos, podendo ser instalado em áreas urbanas ou solos impróprios para a agricultura. A Figura 2 apresenta três diferentes fotobiorreatores.

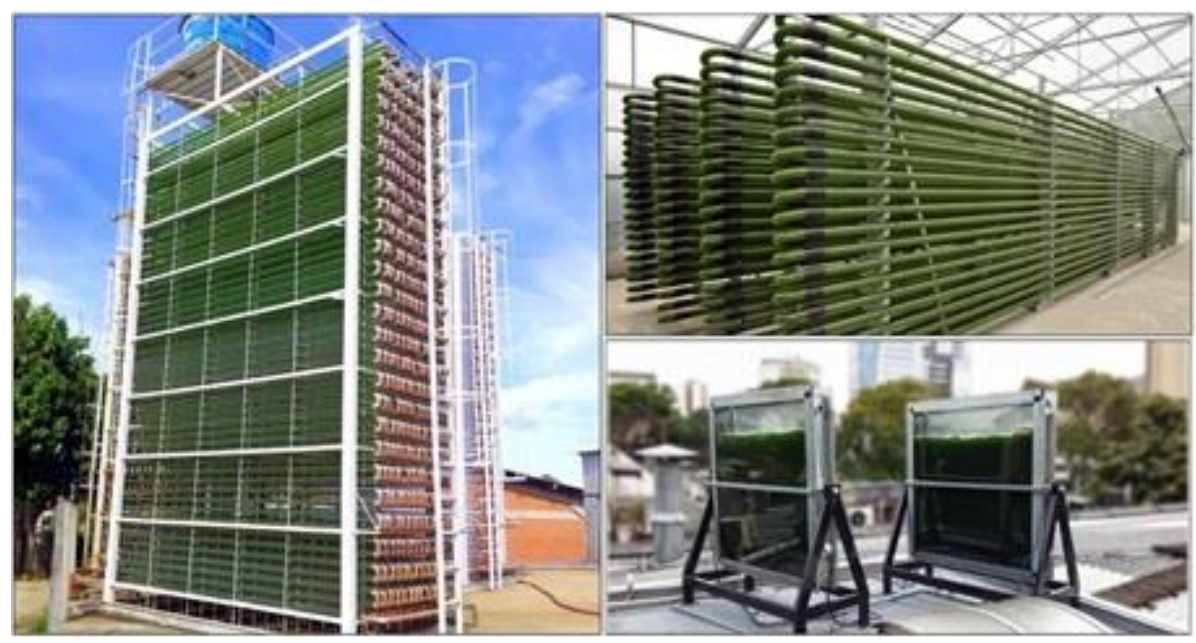

Figura 2. Modelos de fotobiorreatores para cultivo de microalgas. Fonte: Imagem da esquerda e inferior direita acervo da (NPDEAS). Imagem superior direita: IGV Biotech. https://upload.wikimedia.org/wikipedia/commons/b/ba/Photobioreactor PBR 4000 G IGV Biotech.jpg.

Apesar de apresentar melhor controle das condições de cultivo, os fotobiorreatores são financeiramente mais onerosos, demandando maior investimento tecnológico no desenvolvimento de novos arranjos estruturais, materiais construtivos e controle das operações (CHISTI, 2013; GÓMEZ-PÉREZ et al., 2015). Dessa maneira, a viabilidade dos cultivos em escala necessita estar associada à exploração dos potenciais usos dessa tecnologia, em suas diferentes perspectivas. 


\section{Desafios da produção em escala}

A interação entre fatores físicos, químicos e biológicos influencia diretamente no cultivo de microalgas, podendo promover ou inibir seu crescimento. Os fatores biológicos estão associados ao metabolismo celular e à presença de contaminantes no sistema, enquanto os fatores físicos e químicos estão relacionados aos efeitos provocados pela luz, temperatura, $\mathrm{pH}$ e disponibilidade de fontes de carbono e nutrientes (RAVEN, 1990; RICHMOND, 2004; TAIZ; ZEIGER, 2006; DERNER et al., 2006).

\subsection{Fatores físicos e químicos: Luz, temperatura, fonte de carbono e aeração}

Dentre os fatores físicos, talvez o mais importante em cultivos fotoautotróficos seja a iluminação, uma vez que a intensidade luminosa está diretamente relacionada à etapa fotoquímica da fotossíntese, quando ocorre a absorção da luz através de pigmentos como a clorofila, síntese de trifosfato de adenosina (ATP) e a fotólise da água (EBERHARD; FINAZZI; WOLLMAN, 2008). Microalgas são seres fotossintetizantes, de modo que a presença de luz é de suma importância para a manutenção do crescimento celular (GONÇALVES; SIMÕES; PIRES, 2014). Diferentes intensidades luminosas podem promover a produção de diferentes compostos de interesse. Por exemplo, altas intensidades de luz podem induzir o acúmulo de pigmentos, como o $\beta$-caroteno em Dunaliella salina e astaxantina em Haematococcus pluvialis. Entretanto, algumas espécies podem não suportar altas intensidades, podendo sofrer com o fenômeno de fotoinibição (LEVIN et al., 2021), um complexo conjunto de processos moleculares, definidos como a inibição da fotossíntese pelo excesso de luz.

Além da luminosidade, a temperatura possui grande importância nos cultivos de microalgas, uma vez que estas apresentam taxa máxima de crescimento relacionada a uma determinada faixa de temperatura, variando de acordo com a espécie e suas adaptações fisiológicas ao meio no qual vive (NWOBA et al., 2019; RANGLOVÁ et al., 2019). De maneira geral, abaixo ou acima destes valores ocorre redução na velocidade de crescimento, alterações metabólicas, fisiológicas e/ou morte celular.

A temperatura ideal para os cultivos de microalgas, de modo geral, está entre $20^{\circ} \mathrm{C}$ e $24^{\circ} \mathrm{C}$, embora possa variar em função da espécie utilizada. Para 
algumas espécies a elevação da temperatura pode diminuir a quantidade de ácidos graxos insaturados enquanto aumenta a quantidade de ácidos graxos saturados (THOMPSON; GUO; RENAUD, 2004;). Este fator pode contribuir para a produção de biodiesel de melhor qualidade, elevando o número de cetano e aumentando a estabilidade oxidativa do combustível.

Cultivos em escala ocorrem, geralmente, em ambientes externos, portanto, as microalgas experimentam diferentes quantidades de luz e temperatura ao longo do ano. Padronizar os parâmetros de cultivos pode ser um desafio dependendo da espécie utilizada, por esse motivo, a escolha da microalga deve ser muito bem avaliada. Além disso, estratégias de cultivo e o uso da engenharia pode auxiliar em cultivos em larga escala. Um dessas estratégias é optar por espécies capazes de consumir carbono orgânico exógeno.

Embora microalgas sejam organismos fotossintetizantes, sendo algumas delas autótrofas estritas, existem espécies capazes de crescer na total ausência de luz, desde que haja um substrato orgânico (CHEN; JOHNS, 1996). Microalgas podem assimilar uma grande variedade de carbono orgânico, como glucose, acetato e glicerol (LIANG, SARKANY; CUI, 2009; DEVI, SUBHASH; MOHAN, 2012), frutose, lactose, galactose e manose (LIU et al., 2010) e sacarose (CHENG et al., 2009). Entretanto, o uso de carbono orgânico pode encarecer o processo, de modo que pesquisadores têm estudado diversos resíduos ricos em carbono orgânico para o uso em cultivos heterotróficos. Xu, Miao e Wu (2006) utilizaram pó de milho hidrolisado como fonte de carbono orgânico e conseguiram $2 \mathrm{~g} \cdot \mathrm{L}^{-1} \mathrm{dia}^{-1}$ de biomassa seca e $932 \mathrm{mg} \mathrm{L}^{-1} \mathrm{dia}^{-1} \mathrm{de}$ lipídeos. Outros resíduos têm sido testados, como bagaço da cana hidrolisado, resíduo doméstico (DEVI, SUBHASH; MOHAN, 2012), peixe processado (QUEIROZ et al., 2013) e efluente de avicultura (LOWREY; YILDIZ, 2014).

Por não necessitar de luz, é possível manter cultivos heterotróficos com grandes volumes, consequentemente, o aumento de escala ocorre com maior facilidade (LI; XU; WU, 2007). Por outro lado, alguns compostos de alto valor agregado são produzidos em maiores concentrações apenas na presença de luz, por exemplo, os carotenoides. Nesse sentido, cultivo em condição mixotrófica pode ser uma alternativa mais atraente. Cultivos mixotróficos possuem a vantagem de utilizar eficientemente a luz disponível, carbono 
inorgânico (geralmente $\mathrm{CO}_{2}$ ) e carbono orgânico. Esse arranjo resulta em maiores rendimentos de células por unidade de energia de entrada (YANG; HUA; SHIMIZU, 2000).

Outro fator físico relevante para a máxima geração de biomassa é a aeração. Em cultivos densos ou em grandes volumes é necessária a utilização de sistemas de aeração que proporcionem o borbulhamento de ar ou mistura de gases no interior dos cultivos. Esse processo de mistura do meio possibilita às células melhor aproveitamento da luz, proporciona a homogeneização de nutrientes e favorece a troca gasosa, como consequência acaba por aumentar a produtividade de biomassa (UGWU; AOYAGI; UCHIYAMA, 2008). Um fator que possui fundamental importância para o crescimento das microalgas em cultivo é a concentração de $\mathrm{CO}_{2}$ injetado nos sistemas, sendo comumente empregado o uso de fontes diversas para aumentar a produção de biomassa (YANG et al., 2017).

$\mathrm{Na}$ literatura científica são relatados resultados de produção de biomassa de microalgas do gênero Scenedesmus em cultivo autotrófico com adição de $\mathrm{CO}_{2}$ em concentrações variando entre 2 e $20 \%$, alcançando resultados de geração de biomassa significativamente superior ao uso do ar ambiente (BASU et al., 2013; HUANG et al., 2020; RODAS-ZULUAGA et al., 2021). Além de dados da utilização de $\mathrm{CO}_{2}$ puro aos cultivos, é possível encontrar resultados da adição de emissões diversas, desde a utilização de gases originários da combustão de diesel, carvão ou resíduos sólidos (MAEDA et al., 1995; LEE et al., 2002; WANG et al., 2008; JIANG et al., 2013; SINGH et al., 2019).

A utilização de emissões depende fortemente do projeto de desenvolvimento dos fotobiorreatores para permitir que as microalgas façam o uso eficaz das emissões e iluminação sem comprometer a produção de biomassa (ZIMMERMAN et al., 2011; NWOBA et al, 2019). Há diversos modelos de fotobiorreatores, porém, os mais comuns encontrados na literatura são três: tubular, tipo airlift e placa plana. Desses, os fotobiorreatores do tipo airlift são os mais eficientes para mitigação do $\mathrm{CO}_{2}$, uma vez que a circulação do cultivo é promovida pela injeção de gás na parte inferior do sistema (ZIMMERMAN et al., 2011).

A produção de biomassa em larga escala pode ser bastante desafiadora, o alto custo dos nutrientes, assim como o volume de água utilizado podem 
parecer proibitivos. Porém, a utilização de efluentes e emissões surgem como alterativas que viabilizam o escalonamento de microalgas e tornam o processo ainda mais sustentável (YADAVALLI; HEGGERS, 2013; HALIM et al., 2016.

\subsection{Fatores biológicos: Contaminação e formação de biofilme}

Cultivos de microalgas em larga escala devem ser constantemente monitorados quanto à contaminação. Mesmo em fotobiorreatores, os cultivos estão expostos a diferentes fontes de contaminação contendo microrganismos indesejáveis. Contaminações podem ser vistas como algo muito problemático para a produção de biomassa e podem comprometer a obtenção dos bioprodutos desejados. De fato, alguns microrganismos afetam negativamente o crescimento das microalgas, isso porque podem favorecer a formação de biofilmes incrustantes e corrosivos (ZERIOUH et al., 2017). Em cultivo de microalgas, o biofilme é formado nas paredes dos tubos ou das placas de fotobiorreatores, de modo que impedem a passagem da luz (BELOHLAV et al., 2020). Ademais, dependendo da espécie de microrganismo presente, pode haver a liberação de compostos que reduzem o crescimento das microalgas (WANG et al., 2013).

O controle da pureza dos cultivos pode ser especialmente desafiador, uma vez que a contaminação por outros microrganismos pode ocorrer pelo ar injetado no cultivo ou mesmo pela água utilizada. As condições dos cultivos em grande escala podem facilmente sair do controle (WANG et al., 2013). Para sanar essa situação, o uso de filtros na entrada de ar e água pode ser bastante útil. Esterilizar grandes volumes de água seria muito custoso, assim, um filtro capaz de reter micropartículas pode ser uma solução simples e relativamente barata. Quando a formação de biofilme ocorre na presença de algum contaminante o resultado pode ser desastroso, apesar de algumas espécies de microalgas serem capazes de aderir isoladamente em determinados substratos.

Algumas pesquisas têm estudado a viabilidade do uso de biofilmes para acúmulo de compostos de interesse biotecnológico e focado no desenvolvimento de fotobiorreatores que facilitam a formação e a raspagem do biofilme formado. Tipo de substrato, $\mathrm{pH}$, turbulência do líquido, espécie de microalga e presença de bactérias influenciam na adesão das células. Alguns desses fatores são mais importantes na adesão inicial, como o substrato e a presença de um filme de bactérias, outros são mais importantes na manutenção e aumento da espessura 
do biofilme, como o $\mathrm{pH}$, a turbulência e o formato da célula de microalgas (WANG et al., 2018).

Estudos mostram que a diferentes espécies de microalgas são capazes de acumular maiores teores de carboidratos, proteínas, lipídeos e pigmentos, além de aumentar a taxa de consumo de nitrogênio e $\mathrm{CO}_{2}$ (HUANG et al., 2017; PENG et al., 2020, SUN et al., 2020) quando cultivadas em sistemas com a formação de biofilmes. Aprimorar esse método e associá-lo a obtenção de produtos da biomassa de microalga úmida pode ser um caminho que viabilize a produção de biodiesel de microalgas.

\subsection{Controle das condições de cultivo e automação da produção}

Como mencionado nos tópicos anteriores, o crescimento de microalgas exige uma combinação de condições que envolve a manutenção de pH, luz, temperatura, nutrientes e controle da contaminação. Quando o objetivo é aumentar produção de biomassa e compostos de interesse biotecnológico, garantir alguns parâmetros pode ser bastante útil e, em alguns casos, essencial. Alguns fatores podem apenas reduzir a taxa de crescimento, porém outros podem levar à morte abrupta de um cultivo, além disso, quanto maior o valor biotecnológico do composto, maior a exigência de se manter a qualidade e excelência dos processos produtivos (LIANG et al., 2019). Dessa maneira, o uso de controladores pode ser necessário, principalmente, se o cultivo em questão exige maiores cuidados, dependendo da espécie, ou se há uso de efluentes ou injeção de emissões.

Os principais controladores para cultivos de microalgas estão relacionados com a medição de $\mathrm{pH}, \mathrm{CO}_{2}$ e $\mathrm{O}_{2}$ dissolvidos, intensidade luminosa, temperatura, concentração celular (BENAVIDES et al., 2015; BOROWIAK et al., 2021). Há ainda sensores mais específicos, como os de hidrogênio, utilizados em cultivos de microalgas capazes de produzir esse gás em maiores volumes (DIAS et al., 2019). Em sistemas de cultivo semicontínuo ou contínuo, o uso de controladores é de grande importância na troca do meio de cultura para manutenção do crescimento celular constante.

Os sensores de pH possuem uma utilização extra, pois a injeção de $\mathrm{CO}_{2}$ ocasiona a redução do $\mathrm{pH}$ do meio de cultivo. Quando as células estão consumindo dióxido de carbono, o pH aumenta, assim, um pHmetro pode avaliar 
indiretamente se a injeção de $\mathrm{CO}_{2}$ está acima ou abaixo da capacidade do consumo das microalgas. O acoplamento de um dosador de $\mathrm{CO}_{2}$ a um controlado de $\mathrm{pH}$ possibilita o equilíbrio entre o fornecimento de $\mathrm{CO}_{2}$ para a realização da fotossíntese enquanto mantém o pH estável (ERBLAND et al., 2020).

O crescimento celular é um parâmetro importante em cultivos de microalgas e a produção de biomassa em ambientes externos pode ser afetada de diferentes maneiras. Tanto em cultivos em ambientes externos, como os mantidos sob regime contínuo, o uso de controladores pode proporcionar muitos benefícios. Em cultivos contínuos há entrada de meio de cultura novo e saída de meio contendo células de microalgas constantemente. Sob condições de estado estacionário, a concentração da biomassa deve ser controlada ajustando a taxa de diluição (TANG et al., 2012). Altos ganhos de biomassa podem ser obtidos se a taxa de crescimento se mantiver constante, assim o uso de sensores de concentração celular automatizado é altamente desejável, sendo que os mais empregados são aqueles que utilizam técnicas não invasivas, como os que medem absorbância e fluorescência da célula.

Sensores que detectam a fluorescência celular são bastante úteis, especialmente quando a espécie cultivada produz pigmentos de alto valor agregado, embora não se limite a essa única função, pois a análise da fluorescência pode dar respostas em relação à fisiologia celular. A degradação da clorofila é, geralmente, indício de que o cultivo está em condições adversas. A reversão dessa situação deve ser realizada logo no início da descoberta para aumentar as chances de uma recuperação rápida. Marxen et al. (2005) desenvolveram um sensor que mede a fluorescência da clorofila, no entanto, a mediação da fluorescência de outros pigmentos, como astaxantina ou outro carotenoide, pode ser empregado com a mesma finalidade.

Alguns sensores possuem alto custo de fabricação e manutenção, assim algumas pesquisas têm direcionado os esforços para a elaboração de sensores de baixo custo. Benavides et al. (2015) desenvolveram um sensor utilizando LEDs (Light Emitting Diode) que mede a turbidez do meio. Para tanto, os autores construíram uma caixa escura onde um tubo plástico transparente (para passagem da cultura celular) era localizado entre sensor RGB (Red, Green, Blue) e um espelho. O sensor utilizado nesse trabalho é capaz de detectar e 
gerar a luz RGB, de modo que a luz atravessa o cultivo, reflete no espelho e é detectado pelo sensor. D'Agostin (2017) utilizou lâmpadas LED com pico de emissão em $517 \mathrm{~nm}$ para medir a turbidez do meio a partir da luz transmitida. Nesse estudo uma cubeta de acrílico, com $1 \mathrm{~cm}$ de caminho óptico, localizada entre o LED e o sensor foi montado e revestido com material opaco para evitar interferência da luz externa. Assim, a luz emitida atravessa a cubeta e o sensor faz a leitura, quanto menor a quantidade de luz atravessando, maior é a concentração celular.

A utilização de sensores que medem a densidade óptica aprimora 0 sistema de cultivo e produção de compostos, aumentando a qualidade da produção em escala. No entanto, alguns fatores devem ser levados em consideração. Os equipamentos devem ser muito bem calibrados, pois algumas organelas celulares podem influenciar na leitura, além disso, a composição celular pode mudar com o tempo. Desta maneira, associar mais de uma medida de acompanhamento pode diminuir erros (NEDBAL et al., 2008). Em função da versatilidade da utilização de sensores para acompanhamento e controle dos cultivos, a associação de sensores com diferentes finalidades pode ser uma alternativa mais atraente, com o uso combinado de sensores de densidade óptica com sensores de $\mathrm{O}_{2}$ e $\mathrm{CO}_{2}$ (CERVENÝ et al., 2009).

\subsection{Recuperação da biomassa}

Um dos maiores custos na produção de microalgas refere-se à coleta da biomassa. Cultivos de microalgas são relativamente diluídos, de modo que grandes volumes precisam ser manipulados para recuperação da biomassa (GRIMA et al., 2003). Os principais mecanismos de separação de biomassa empregados são a floculação, a filtração, a flotação, a centrifugação, ou ainda a utilização de duas ou mais técnicas combinadas. A técnica empregada para a coleta depende das características das células de microalgas, como forma e tamanho, densidade do cultivo, da aplicação da biomassa (BRENNAN; OWENDE, 2010).

Os processos de centrifugação e eletro flotação apresentam elevada eficiência, embora o elevado consumo energético reduza sua viabilidade; por outro lado, a filtração possui baixo custo financeiro, mas necessita de trabalho braçal constante para troca de filtros e demanda mais tempo de trabalho 
individual; por fim, a floculação é um processo de baixo custo energético, embora a escolha do agente floculante deva ser observada com cautela, a fim de reduzir custos operacionais elevados (UDUMAN; QI; DANQUAH, 2010; CHEN et al., 2011). De todas essas técnicas, a que apresenta menor custo é a floculação, e consiste na adição de compostos capazes de promover a agregação das células em suspensão, aumentando sua densidade e favorecendo a decantação, com a consequente concentração da biomassa.

Vários agentes químicos têm sido utilizados para essa finalidade, incluindo os sais de metais de cátions polivalentes como $\mathrm{Al}_{2}\left(\mathrm{SO}_{4}\right)^{3}, \mathrm{Fe}_{2}\left(\mathrm{SO}_{4}\right)^{3}$, e $\mathrm{FeCl}_{3}$; e os coagulantes naturais de origem vegetal e animal, como a quitosana e os taninos, que são polímeros policatiônicos naturais e biodegradáveis de ampla aplicabilidade industrial (SELESU et al., 2016). As vantagens da utilização de agentes floculantes orgânicos consiste em não ocasionarem a contaminação da biomassa impossibilitando sua utilização e de seus compostos, além de possui um apelo ambiental em função da disposição final dos resíduos gerados no processo.

\section{Oportunidades da produção em escala}

A produção de microalgas em larga escala enfrenta algumas dificuldades, como produção de inóculo, alto custo e, em caso de cultivos em ambientes externos, variação das condições climáticas. Alguns desses impasses podem ser resolvidos com estratégias que envolvem o uso de emissões, efluentes, manutenção de cultivos mixotróficos e heterotróficos, além de permitir a obtenção de bioprodutos diversos.

\subsection{Tratamento de efluentes e emissões}

Por meio da fotossíntese, as microalgas convertem a energia luminosa do Sol em energia bioquímica. A integração entre sistemas geradores de emissões gasosas e o cultivo de microalgas se apresenta como uma possibilidade bastante factível, resultando não somente no aumento da produtividade de biomassa, como também realizando o tratamento desses gases.

Atualmente existem alguns métodos voltados para a purificação de emissões, tais como purificação por membrana, por lavagem de gás, por 
criogenia, por adsorção e por via biológica (ZHAO; SU, 2014). Do ponto de vista técnico, todas essas metodologias são viáveis, entretanto, a técnica de fixação biológica tem sido considerada uma escolha promissora, além de sustentável uma vez que, ao fixar $\mathrm{CO}_{2}$ o organismo fotossintetizante produz biomassa rica em compostos de interesse biotecnológico (SPOLAORE et al., 2006; PULZ; GROSS, 2004). Nesse cenário, surgem as microalgas que possuem a vantagem de ter um rápido crescimento e maior eficiência fotossintética (FRANCO et al., 2013).

A utilização de $\mathrm{CO}_{2}$ como fonte de carbono em cultivos de microalgas promove aumento da produtividade de biomassa, lipídeos e demais compostos. De acordo com Suali e Sarbatly (2012), a suplementação do ar atmosférico com $5 \%$ de $\mathrm{CO}_{2}$ resultou no aumento de $63 \%$ da produção de lipídeos em cultivos de Chlorella emersonii. Os mesmos bons resultados estão sendo encontrados em experimentos utilizando emissões industriais, como o trabalho realizado por Tastan et al. (2013) que avaliou os efeitos dos gases originários da queima de gás liquefeito de petróleo (GLP) e gasolina (GSN) no crescimento das microalgas Phormidium sp. e Chlorella sp. A utilização de gases de exaustão de um gerador a diesel levou ao aumento de até $287 \%$ na produção de lipídeos (CORRÊA, 2015) e 1,8 vezes na produção de biomassa (FINGER, 2017). Interessantemente, não foi observado inibição de crescimento na presença de outros gases, como $\mathrm{CO}$ e espécies de óxido de nitrogênio da microalga Scenedesmus obliquus (atualmente Tetradesmus obliquus).

A combinação do uso de emissões com o tratamento de efluentes pode promover ganhos em relação ao acúmulo de compostos de interesse. Miyawaki (2013) observou que a injeção de biogás contendo $37 \%$ de $\mathrm{CO}_{2}$ promoveu um aumento no número de células e o teor de lipídeos em cultivos de Scenedesmus disciformes mantidas em efluente suíno, bovino e esgoto sanitário.

O uso das microalgas na biorremediação de efluentes urbanos e agroindustriais tem sido exaustivamente estudado (OBAJA et al., 2003; JIMENEZ-PEREZ et al., 2004; FIERRO; SANCHEZ-SAAVEDRA; COPALCUA, 2008). Dados da literatura trazem resultados promissores em relação à biorremediação de efluente suíno e aumento da produção de biomassa de microalgas (OBAJA et al., 2003; OBAJA; MACE; MATA-ALVAREZ, 2005; KIM et al., 2007; TAHER, 2013). Mulbry et al. (2008) obtiveram uma produtividade de 
biomassa de $24 \mathrm{~g} \mathrm{~m}^{-2} \mathrm{~d}^{-1}$ com taxas de incorporação de nitrogênio e fósforo de 1,8 e $0,3 \mathrm{~g} \mathrm{~m}^{-2} \mathrm{~d}^{-1}$, respectivamente. Além do aumento da produção de biomassa, as microalgas são capazes de reduzir o teor da carga orgânica (COD), chegando a uma redução de mais de 65\% (JIMENEZ-PEREZ et al., 2004; DICHTL; ROGGE; BAUERFELD, 2007; MULBRY et al., 2008; WANG, BLUCK; VAN WIE, 2014).

Efluentes representam um passivo ambiental de grande relevância, uma vez que a alta carga orgânica pode gerar a eutrofização de rios, se não tratado adequadamente. Por essa razão, o emprego dos cultivos de microalgas como ferramenta para biorremediação se apresenta como uma das principais potencialidades dessa tecnologia, sobretudo quando associada a outros processos biotecnológicos para obtenção de bioprodutos e moléculas bioativas.

\subsection{Obtenção de bioprodutos}

O consumo de microalgas foi amplamente realizado por tribos indígenas durante séculos. Chineses já consumiam espécies de Nostoc, Spirulina e Aphanizomenon há centenas de anos (JENSEN; GINSBERG; DRAPEAU, 2001). Os primeiros cultivos de microalgas tinham como objetivo compreender a metodologia para cultivo e estiveram ligados a estudos bacteriológicos. No entanto, após 1940, os experimentos com cultivos de microalgas saíram dos estudos básicos e passaram para os estudos relacionados a aplicações biotecnológicas com cultivos em grandes escalas (BOROWITZKA, 1999). Atualmente, dada a importância econômica das diferentes aplicações para a biomassa de microalgas, os estudos estão voltados para o aumento da produtividade de biomassa, lipídeos para produção de biocombustíveis e produtos de valor agregado.

Após 1948 nos Estados Unidos, Alemanha e Japão, as microalgas surgiram como alternativa à suplementação alimentar (BOROWITZKA, 1999), nesse mesmo período, tiveram início as pesquisas acerca de substâncias biologicamente ativas a partir da biomassa de microalgas (BOROWITZKA, 1995). Tendo em vista a composição de biomassa de microalgas rica em compostos essenciais para alimentação humana e animal, alguns estudos já demostraram a possibilidade de suplementar alimentação e em ração de aves (GINZBERG et al., 2000), peixes (BALEN et al., 2016) e cães (LIRIO, 2019). 
Além do teor nutricional, as microalgas têm potencial para a produção de uma variedade de produtos, como pigmentos (clorofila, carotenoides, ficobilina), compostos bioativos (vários compostos antibacterianos, antifúngico, antiviral, antiprotozoário), proteínas, polissacarídeos ( $\beta$ 1,3-glucana, carragenana, amido, alginatos, celulose), biopoliesteres e lipídeos (poli-insaturados, ácidos graxos e hidrocarbonetos).

Microalgas são uma importante fonte de pigmentos, como a clorofila e os carotenoides. Esses pigmentos são aplicados com sucesso na área alimentar, em cosméticos e na indústria farmacêutica. O pigmento em maior concentração nas células de microalgas é a clorofila, o principal pigmento responsável por captar os fótons em organismos fotossintetizantes. A clorofila é um diéster e pode ser saponificado por tratamento alcalino, dando origem à clorofilina. Esses derivados são importantes corantes utilizados na alimentação, em indústrias têxteis e de papel (MORTENSEN; GEPPEL, 2007). Ademais, estudos indicam que a clorofilina possui ação antitumoral (DIAZ; LI; DASHWOOD, 2003).

Outra classe de pigmentos presente em células de microalgas são os carotenoides. Astaxantina, xantofilas, zeaxantina, cantaxantina, equinenona, e $\beta$-caroteno são exemplos de carotenoides. Além da proteção do aparato fotossintético, carotenoides possuem grande importância na natureza, como coloração de penas de aves, peixes, anfíbios e répteis para mostrar sua aptidão (baixa carga parasitária e alta ingestão calórica). Pigmentação por astaxantina atua ainda na atração de potenciais parceiros sexuais, assim como na indicação do nível social (BLOUNT; MCGRAW, 2008). Ademais, carotenoides podem ser importantes no anúncio de toxicidade ou coloração adequada para camuflagem (STODDARD, 2012). Tais pigmentos exercem um papel importante nas células, pois absorvem o excesso de energia luminosa, evitando que a clorofila sofra fotooxidação. Os carotenoides são excelentes antioxidantes e servem como precursor da vitamina A. Murthy et al. (2005) investigaram a microalga Dunaliella salina como matéria prima para produção de carotenoides e avaliaram a atividade biológica desse composto. Os resultados desse estudo mostraram que as atividades dos carotenoides de microalga superam a atividade de carotenoides sintéticos.

Outro carotenoide de grande relevância no cenário comercial é a astaxantina, a qual tem importantes aplicações nas indústrias farmacêuticas e 
de cosmética, e em indústrias de suplementação humana e ração animal. Os benefícios para a saúde humana têm sido relatados pela literatura científica, tais como: ação antioxidante, fotoproteção, manutenção da saúde dos olhos, da pele, das células e do coração, tratamento de doenças inflamatórias, propriedades antitumorais, aumento da resposta imune e tratamento de doenças degenerativas (GUERIN; HUNTLEY; OLAIZOLA, 2003). Além dos benefícios à saúde, estudos demonstram que uma dieta baseada em astaxantina produzida pela microalga Haematococcus pluvialis não possui efeitos tóxicos (GUERIN; HUNTLEY; OLAIZOLA, 2003).

Outro grupo de moléculas com potenciais aplicações é o dos carboidratos, devido ao potencial de aplicação terapêutica que apresentam. Estudos com o composto $\beta$ 1,3-glucana têm mostrado que esse composto é um imunoestimulador, antioxidante e redutor do colesterol no sangue e foi encontrado em cepas de Chlorella (SPOLAORE, 2006). Além da aplicação nutricional, alguns carboidratos como polissacarídeos sulfatados podem ser aplicados em terapias antiadesivas em infecções bacterianas. Outros carboidratos de interesse são alginatos, celulose ou carragenanas que são utilizados como emulsificantes e estabilizantes em vários produtos alimentícios (KOLLER; MUHR; BRAUNEGG, 2014).

Dentre os compostos já comercializados de microalgas pode-se citar os ácidos graxos, como o DHA e o EPA, extraídos da biomassa de Schizochytrium sp. Apesar de um dos principais destinos para os lipídeos de microalga ter sido a produção de biodiesel, as células de microalgas são ricas em ácidos graxos de alto valor agregado. Muitas espécies de microalgas contêm ácidos graxos poliinsaturados, como o ácido eicosapentaenóico (EPA), ácido docosahexaenóico (DHA), ácido linoléico (GLA) e o ácido araquidônico ( $A A)$. Esses ácidos graxos podem ser comercializados para aplicações farmacêuticas ou terapêuticas. Alguns ácidos graxos livres têm sido estudados como compostos antimicrobianos (MOLINA-CÁRDENAS; SÁNCHES-SAAVEDRAS; LIZÁRRAGA-PARTIDA, 2014).

No escopo da utilização dos compostos microalgais em atividades relacionadas ao controle biológico, as moléculas presentes na biomassa e extratos de algumas espécies possuem potencial atividade antimicrobiana, como demonstrado Ghasemi et al. (2007), que obtiveram resultados positivos na 
utilização de extratos aquosos e orgânicos de Chroococcus dispersus, Chlamydomonas reinhardtii e Chlorella vulgaris frente ao crescimento de fungos e bactérias. De maneira similar, Dantas et al. (2019) testaram os efeitos de extratos aquosos e orgânicos de Scenedesmus subspicatus no crescimento de Klebsiella pneumoniae, Bacillus subtilis e Escherichia coli, com resultados promissores obtidos em diferentes solventes. Em outro estudo, Santoyo et al. (2009) determinaram a atividade antimicrobiana de extratos orgânicos de Hematococcus pluvialis contra Staphylococcus aureus, Escherichia coli, Candida albicans e Aspergillus niger, com melhores resultados obtidos utilizando extratos etanólicos.

Alguns estudos mostram ainda o potencial das microalgas na agricultura, indicando atividade fungicida contra fitopatógenos. Ördög et al. (2004) obtiveram extratos aquosos de diferentes espécies de microalgas (Cyanobacteria e Chlorophyte) e os avaliaram quanto à atividade biológica contra diferentes espécies de fungos filamentosos e bactérias, incluindo fitopatógenos. Extratos de duas clorófitas, Desmococcus olivaceus e Scenedesmus sp. apresentaram atividade bactericida contra Pseudomonas syringae e atividade fungicida contra Alternaria sp., respectivamente. Somada a atividade antifúngica, as microalgas aplicação como biofertilizantes. Mazepa et al. (2021) avaliaram a aplicação da biomassa e do extrato aquoso da microalga Desmodesmus subspicatus na germinação e crescimento de plantas de alface, identificando a presença de glicosídeos e da citocinina natural zeatina, responsáveis pela atividade observada. Além da aplicação diretamente no campo, os extratos das microalgas D. subspicatus, Chlorella vulgaris e Messastrum gracile demonstraram potencial aplicação na propagação in vitro de oruídeas, ampliando as possibilidades de aplicação das microalgas na agricultura (CORBELLINI et al., 2020; NAVARRO et al., 2021).

\subsection{Produção de biomassa, bioprodutos e integração de processos}

O Núcleo de Pesquisa e Desenvolvimento de Energia Autossustentável (NPDEAS) é um grupo de pesquisa multidisciplinar da Universidade Federal do Paraná (UFPR) localizado na cidade de Curitiba-PR, que busca explorar diversos processos biotecnológicos, tendo como principal atividade o cultivo de microalgas em fotobiorreatores em escala industrial. Inicialmente, o objetivo do 
grupo era atingir a autossuficiência energética através da produção de biodiesel gerado com os lipídeos provenientes da biomassa microalgal. Atualmente a planta industrial do NPDEAS integra diferentes módulos e processos, visando a obtenção de diferentes produtos (Figura 3).

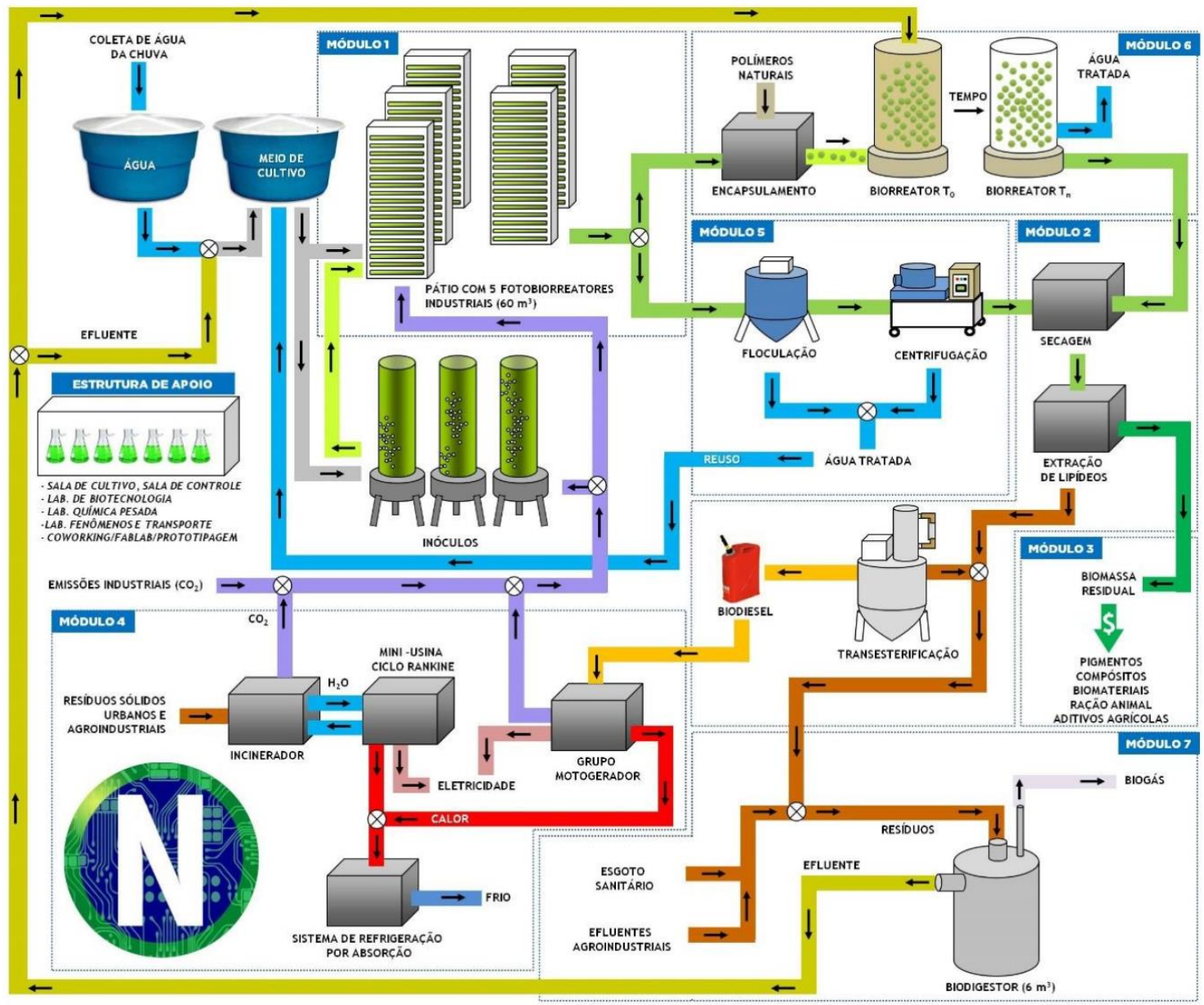

Figura 3. Diagrama esquemático dos módulos de produção do NPDEAS.

Dentre os processos diretamente relacionados à produção de biomassa em escala é possível destacar o cultivo de microalgas em fotobiorreatores com volume de $12 \mathrm{~m}^{3}$, tratamento de efluentes agroindustriais, tratamento de emissões de sistema de incineração de resíduos sólidos urbanos (RSU), unidade de recuperação, centrifugação, secagem e processamento da biomassa para extração de compostos e obtenção de bioprodutos. Além dessas atividades, a planta do NPDEAS integra outros processos modulares: 
- Módulo 1: Unidade de fotobiorreatores, onde as microalgas são cultivadas em sistemas de diferentes volumes e modelos para produção de biomassa;

- Módulo 2: Unidade de secagem da biomassa de microalgas e produção de biodiesel;

- Módulo 3: Unidade de processamento de biomassa residual para bioprodutos (pigmentos, compósitos, ração animal, biomateriais);

- Módulo 4: Unidade de geração de energia elétrica e refrigeração por absorção através de incineração de resíduos sólidos urbanos (RSU) e grupo motogerador, para geração de energia elétrica com diferentes combustíveis;

- Módulo 5: Unidade de floculação e centrifugação para produção de água tratada, pós cultivo de microalgas e tratamento terciário de efluentes;

- Módulo 6: Unidade de encapsulamento de microalgas para tratamento de efluentes e produção de água tratada,

- Módulo 7: Unidade de Biodigestão para tratamento de efluentes brutos, geração de biogás e efluente biodigerido utilizado como meio de cultura para o cultivo de microalgas no módulo 1.

Além de funcionarem de maneira integrada, as unidades permitem o desenvolvimento de diferentes produtos que atendem um amplo espectro de atividades no mercado. A concepção modular do sistema permite ainda a futura comercialização dos sistemas completos, ou separadamente conforme a demanda.

O destaque dos cultivos de microalgas para produção de biomassa e desenvolvimento dos demais processos pode ser avaliado pelo número de publicações em revistas científicas indexadas nos últimos dez anos. Desde sua criação em 2008, alunos de pós-graduação de diferentes áreas desenvolveram suas pesquisas no NPDEAS, o que resultou em publicações em diferentes áreas do conhecimento, como Genética, Bioquímica, Ciência dos Materiais, Engenharia Mecânica e Engenharia Química, evidenciando a pluralidade de oportunidades que a produção de microalgas e a integração de processos oferece. O Quadro 1 apresenta algumas das publicações relacionadas ao cultivo de microalgas realizadas por integrantes do NPDEAS nos últimos dez anos. 
Quadro 1. Artigos científicos publicados pelo NPDEAS ao longo da última década.

\begin{tabular}{|c|c|c|}
\hline Área de pesquisa & Título do trabalho & Referência \\
\hline \multirow{8}{*}{$\begin{array}{l}\text { Modelagem e simulação } \\
\text { da produção de } \\
\text { biomassa e outros } \\
\text { processos }\end{array}$} & $\begin{array}{l}\text { A simplified mathematical model to predict PVC } \\
\text { photodegradation in photobioreactors }\end{array}$ & $\begin{array}{l}\text { D'Aquino et } \\
\text { al., } 2012\end{array}$ \\
\hline & $\begin{array}{l}\text { Mathematical model of the } \mathrm{CO}_{2} \text { solubilization } \\
\text { reaction rates developed for the study of } \\
\text { photobioreactors }\end{array}$ & $\begin{array}{l}\text { Sugai- } \\
\text { Guérios et } \\
\text { al., } 2013\end{array}$ \\
\hline & $\begin{array}{l}\text { The microalgae derived hydrogen process in } \\
\text { compact photobioreactors }\end{array}$ & $\begin{array}{l}\text { Vargas et } \\
\text { al., } 2014\end{array}$ \\
\hline & $\begin{array}{l}\text { Mass transfer modeling and maximization of } \\
\text { hydrogen rhythmic production from genetically } \\
\text { modified microalgae biomass }\end{array}$ & $\begin{array}{l}\text { Vargas et } \\
\text { al., } 2016\end{array}$ \\
\hline & $\begin{array}{l}\text { Modeling microalgae derived hydrogen production } \\
\text { enhancement via genetic modification }\end{array}$ & $\begin{array}{l}\text { Vargas et } \\
\text { al., } 2016\end{array}$ \\
\hline & $\begin{array}{l}\text { The experimental validation of a large-scale } \\
\text { compact tubular microalgae photobioreactor model }\end{array}$ & $\begin{array}{l}\text { Ribeiro et } \\
\text { al., } 2017\end{array}$ \\
\hline & $\begin{array}{l}\text { Modeling, simulation, and optimization of a } \\
\text { microalgae biomass drying process }\end{array}$ & $\begin{array}{l}\text { Disconzi et } \\
\text { al., } 2019\end{array}$ \\
\hline & $\begin{array}{l}\text { Experimental calibration of a biohydrogen } \\
\text { production estimation model }\end{array}$ & $\begin{array}{l}\text { Dias et al., } \\
2019\end{array}$ \\
\hline \multirow{8}{*}{$\begin{array}{l}\text { Cultivo, produção e } \\
\text { recuperação da } \\
\text { biomassa em } \\
\text { fotobiorreatores }\end{array}$} & $\begin{array}{l}\text { Energy analysis of lipid extraction of Scenedesmus } \\
\text { sp. produced in pilot scale }\end{array}$ & $\begin{array}{l}\text { Schroeder } \\
\text { et al., } 2015\end{array}$ \\
\hline & $\begin{array}{l}\text { Maximum microalgae biomass harvesting via } \\
\text { flocculation in large scale photobioreactor } \\
\text { cultivation }\end{array}$ & $\begin{array}{l}\text { Selesu et } \\
\text { al., } 2016\end{array}$ \\
\hline & $\begin{array}{l}\text { Thermal treatment of clay-based ceramic } \\
\text { membranes for microfiltration of Acutodesmus } \\
\text { obliquus }\end{array}$ & $\begin{array}{l}\text { Henriques } \\
\text { et al., } 2017\end{array}$ \\
\hline & $\begin{array}{l}\text { Optimization of flocculation with tannin-based } \\
\text { flocculant in the water reuse and lipidic production } \\
\text { for the cultivation of Acutodesmus obliquus }\end{array}$ & $\begin{array}{l}\text { Hesse et } \\
\text { al., } 2017\end{array}$ \\
\hline & $\begin{array}{l}\text { The harvesting of high lipid content microalgae } \\
\text { biomass through a flocculation strategy }\end{array}$ & $\begin{array}{l}\text { Lemos et } \\
\text { al., } 2018\end{array}$ \\
\hline & $\begin{array}{l}\text { The effect of light intensity on the production and } \\
\text { accumulation of pigments and fatty acids in } \\
\text { Phaeodactylum tricornutum }\end{array}$ & $\begin{array}{l}\text { Conceição } \\
\text { et al., } 2020\end{array}$ \\
\hline & $\begin{array}{l}\text { Enhanced microalgae biomass and lipid output for } \\
\text { increased biodiesel productivity }\end{array}$ & $\begin{array}{l}\text { Morais et } \\
\text { al., } 2021\end{array}$ \\
\hline & $\begin{array}{l}\text { Life cycle assessment of biomass production in } \\
\text { microalgae compact photobioreactors }\end{array}$ & $\begin{array}{l}\text { Silva et al., } \\
2015\end{array}$ \\
\hline
\end{tabular}




\begin{tabular}{|c|c|c|}
\hline \multirow{5}{*}{$\begin{array}{l}\text { Tratamento de efluentes, } \\
\text { emissões e processos } \\
\text { ambientais }\end{array}$} & $\begin{array}{l}\text { Environmental study of producing microalgal } \\
\text { biomass and bioremediation of cattle manure } \\
\text { effluents by microalgae cultivation }\end{array}$ & $\begin{array}{l}\text { Scherer et } \\
\text { al., } 2017\end{array}$ \\
\hline & $\begin{array}{l}\text { Enhanced biohydrogen production from microalgae } \\
\text { by diesel engine hazardous emissions fixation }\end{array}$ & $\begin{array}{l}\text { Corrêa et } \\
\text { al., } 2017\end{array}$ \\
\hline & $\begin{array}{l}\text { A genset and mini-photobioreactor association for } \\
\mathrm{CO}_{2} \text { capturing, enhanced microalgae growth and } \\
\text { multigeneration }\end{array}$ & $\begin{array}{l}\text { Telles et } \\
\text { al., } 2018\end{array}$ \\
\hline & $\begin{array}{l}\text { Environmental evaluation of flocculation efficiency } \\
\text { in the separation of the microalgal biomass of } \\
\text { Scenedesmus sp. cultivated in full-scale } \\
\text { photobioreactors }\end{array}$ & $\begin{array}{l}\text { Scherer et } \\
\text { al., } 2018\end{array}$ \\
\hline & $\begin{array}{l}\text { Microalgae derived biomass and bioenergy } \\
\text { production enhancement through biogas } \\
\text { purification and wastewater treatment }\end{array}$ & $\begin{array}{l}\text { Miyawaki et } \\
\text { al., } 2021\end{array}$ \\
\hline \multirow{5}{*}{$\begin{array}{l}\text { Avaliação de atividade } \\
\text { biológica e obtenção de } \\
\text { bioprodutos diversos }\end{array}$} & Microalgae biodiesel via in situ methanolysis & $\begin{array}{l}\text { Carvalho } \\
\text { Júnior et } \\
\text { al., } 2011\end{array}$ \\
\hline & $\begin{array}{l}\text { A review on microalgae, a versatile source for } \\
\text { sustainable energy and materials }\end{array}$ & $\begin{array}{l}\text { Satyanaray } \\
\text { ana; } \\
\text { Mariano; } \\
\text { Vargas, } \\
2011\end{array}$ \\
\hline & $\begin{array}{l}\text { Effect of defatted microalgae (Scenedesmus } \\
\text { obliquus) biomass inclusion on growth performance } \\
\text { of Rhamdia quelen (Quoy \& Gaimard, 1824) }\end{array}$ & $\begin{array}{l}\text { Balen et } \\
\text { al., } 2016\end{array}$ \\
\hline & $\begin{array}{l}\text { Extraction of Acutodesmus obliquus lipids using a } \\
\text { mixture of ethanol and hexane as solvent }\end{array}$ & $\begin{array}{l}\text { Escorsim et } \\
\text { al., } 2018\end{array}$ \\
\hline & $\begin{array}{l}\text { Diets containing residual microalgae biomass } \\
\text { protect fishes against oxidative stress and DNA } \\
\text { damage }\end{array}$ & $\begin{array}{l}\text { Marques et } \\
\text { al., } 2019\end{array}$ \\
\hline
\end{tabular}

\section{Considerações finais}

Além do potencial científico que os cultivos de microalgas apresentam, a produção de biomassa integrada ao tratamento de efluentes, tratamento de emissões e obtenção de bioprodutos possui enorme potencial de aplicação industrial prática, oferecendo diversas oportunidades para o setor industrial. Para tanto, a integração de diferentes processos, como idealizado no NPDEAS, pode reduzir os custos individuais de produção de moléculas bioativas, biocombustíveis e demais bioprodutos, aumentando a viabilidade técnica e 
econômica, permitindo que as microalgas possam ser utilizadas em uma gama cada vez maior de aplicações.

\section{Agradecimentos}

Os autores agradecem o suporte financeiro do Conselho Nacional de Pesquisa e Desenvolvimento (CNPq) e Coordenadoria de Aperfeiçoamento de Pessoal de Nível Superior (CAPES) através do financiamento de projetos e fornecimento de bolsas de pós-graduação.

\section{Referências}

ASGHARPOUR, M.; RODGERS, B.; HESTEKIN, J. A. Eicosapentaenoic acid from Porphyridium cruentum: Increasing growth and productivity of microalgae for pharmaceutical products. Energies, v. 8, p. 10487-10503, 2015. https://doi.org/10.3390/en80910487.

ASSUNÇÃO, J.; MALCATA, F. X. Enclosed "non-conventional" photobioreactors for microalga production: A review, Algal Research, v. 52, p. 102107, 2020. https://doi.org/10.1016/j.algal.2020.102107.

BALEN, R. E. et al. Effect of defatted microalgae (Scenedesmus obliquus) biomass inclusion on growth performance of Rhamdia quelen (Quoy \& Gaimard, 1824). Journal of Applied Ichthyology, v. 31, p. 98-101, 2016. https://doi.org/10.1111/jai.12969.

BASU, S. et al. Enhanced $\mathrm{CO}_{2}$ sequestration by a novel microalga: Scenedesmus obliquus SA1 isolated from bio-diversity hotspot region of Assam, India. Bioresource Technology, v. 143, p. 369-377, 2013. https://doi.org/10.1016/j.biortech.2013.06.010.

BELOHLAV, V. et al. Effect of hydrodynamics on the formation and removal of microalgal biofilm in photobioreactors. Biosystems Engineering, v. 200, p. 315 - 327, 2020. https://doi.org/10.1016/j.biosystemseng.2020.10.014.

BENAVIDES, M. et al. Design and test of a low-cost RGB sensor for online measurement of microalgae concentration within a photo-bioreactor. Sensors, v. 15, p. 4766-4780, 2015. https://dx.doi.org/ 10.3390/s150304766. 
BLOUNT, J. D.; MCGRAW, K. J. Signal functions of carotenoid colouration. In: BRITTON, G.; LIAAEN-JENSEN, S.; PFANDER, H. Carotenoids. Natural Functions. Birkhäuser Verlag, p. 213-32, 2008.

BOROWIAK, D. et al. Novel, automated, semi-industrial modular photobioreactor system for cultivation of demanding microalgae that produce fine chemicalsThe next story of $H$. pluvialis and astaxanthin, Algal Research, v. 53, p. 102151 , 2021. https://doi.org/10.1016/j.algal.2020.102151.

BOROWITZKA, M. A. Microalgae as sources of pharmaceuticals and other biologically active compounds. Journal of Applied Phycology, v. 7, p. 3-15, 1995. https://doi.org/10.1007/BF00003544.

BOROWITZKA, M. A. Commercial production of microalgae: ponds, tanks, tubes and fermenters. Journal of Biotechnology, v. 70, p. 313-321, 1999. https://doi.org/10.1016/S0168-1656(99)00083-8.

BRENNAN, L.; OWENDE, P. Biofuels from microalgae - a review of technologies for production, processing, and extractions of biofuels and co-products. Renewable and Sustainable Energy Reviews, v. 14, p. 557-577, 2010. https://doi.org/10.1016/j.rser.2009.10.009.

CARVALHO JÚNIOR, R. M. et al. Microalgae biodiesel via in situ methanolysis. Journal of Chemical Technology and Biotechnology, v. 86, p. 1418-1427, 2011. https://doi.org/10.1002/jctb.2652.

CERVENÝ, J. et al. Photobioreactor for cultivation and real-time, in-situ measurement of $\mathrm{O}_{2}$ and $\mathrm{CO}_{2}$ exchange rates, growth dynamics, and of chlorophyll fluorescence emission of photoautotrophic microorganisms. Engineering in Life Sciences, v. 9, p. 247-253, 2009. https://doi.org/10.1002/elsc.200800123.

CHEN, F.; JOHNS, M. R. Heterotrophic growth of Chlamydomonas reinhardtii on acetate in chemostat culture. Process Biochemistry, v. 31, p. 602-604, 1996.

CHENG, Y. et al. Alga-based biodiesel production and optimization using sugar cane as the feedstock. Energy and Fuels, v. 23, p. 4166-4173, 2009. https://doi.org/10.1021/ef9003818. 
CHISTI, Y. Constraints to commercialization of algal fuels. Journal of $\begin{array}{llllll}\text { Biotechnology, v. } & \text { v. } & \text { 201, } & \text { p. } & \text { 2014, }\end{array}$ https://doi.org/10.1016/j.jbiotec.2013.07.020.

CONCEIÇÃO, D. et al. The effect of light intensity on the production and accumulation of pigments and fatty acids in Phaeodactylum tricornutum. Journal of Applied Phycology, v. 32, p. 1017-1025, 2020. https://doi.org/10.1007/s10811-019-02001-6.

CORBELLINI, J. R. et al. Effect of microalgae Messastrum gracile and Chlorella vulgaris on the in vitro propagation of orchid Cattleya labiate. Journal of Applied Phycology, v. 32, p. 4013-4027, 2020. https://doi.org/10.1007/s10811-02002251-9.

CORREAA, D. O. et al. Enhanced biohydrogen production from microalgae by diesel engine hazardous emissions fixation. International Journal of Hydrogen $\begin{array}{lllll}\text { Energy, } & \text { v. } & 42, & \text { p. } & 21463-21475,\end{array}$ https://doi.org/10.1016/j.ijhydene.2017.05.176.

CORRÊA, D. O. Desenvolvimento e caracterização do cultivo de microalgas em fotobiorreator alimentado por emissões gasosas de motores. Dissertação de Mestrado. Curitiba: Universidade Federal do Paraná, 2015.

D'AGOSTIN, D. A. L. Automação de fotobiorreatores para cultivo de microalgas em regime contínuo visando aumento da produtividade. Dissertação de Mestrado. Curitiba: Universidade Federal do Paraná, 2017.

D'AQUINO, C. A. et al. A simplified mathematical model to predict PVC photodegradation in photobioreactors. Polymer Testing, v. 31, p. 638-644, 2012. https://doi.org/10.1016/j.polymertesting.2012.03.002.

DANTAS, D. M. M. et al. Evaluation of antioxidant and antibacterial capacity of green microalgae Scenedesmus subspicatus. Food Science and Technology $\begin{array}{lllllll}\text { International, } & \text { v. } & 25, & \text { n. } & 4, & \text { p. } & 318-326,\end{array}$ https://doi.org/10.1177\%2F1082013218825024.

DERNER, R. B. et al. Microalgas, produtos e aplicações. Ciência Rural, v.36, n 6, p.1959-1967, 2006. https://doi.org/10.1590/S0103-84782006000600050. 
DEVI, M. P; SUBHASH, G. V.; MOHAN, S. V. Heterotrophic cultivation of mixed microalgae for lipid accumulation and wastewater treatment during sequential growth and starvation phases: effect of nutrient supplementation. Renewable Energy, v. 43, p. 276-283, 2012. https://doi.org/10.1016/j.renene.2011.11.021.

DICHTL, N.; ROGGE, S.; BAUERFELD, K. Novel strategies in sewage sludge treatment. Clean-Soil Air Water, v. 35, p. 473-479, 2007. https://doi.org/10.1002/clen.200720022.

DIAS, F. G. et al. Experimental calibration of a biohydrogen production estimation model. Journal of Verification, Validation and Uncertainty Quantification, v. 4, p. 1-10, 2019. https://doi.org/10.1115/1.4044664.

DIAZ, G. D., LI, Q.; DASHWOOD, R. C. Caspase-8 and apoptosis inducing mediate a cytocrome c-independent pathway of apoptosis in human colon cancer cells induced by the dietary phytochemical chlorophyllin. Cancer Research, v. 63, p. 1254-1261, 2003.

DISCONZI, F. P. et al. Modeling, simulation, and optimization of a microalgae biomass drying process. International. Journal of Energy Research, v. 43, p. 3421-3435, 2019. https://doi.org/10.1002/er.4481.

DOLGANYUK et al. Microalgae: A promising source of valuable bioproducts. Biomolecules, v. 10, 2020. doi:10.3390/biom10081153.

EBERHARD, S.; FINAZZI, G.; WOLLMAN, F-A. The dynamics of photosynthesis. Annual Reviews of Genetics, v. 42, p. 463-515, 2008. 10.1146/annurev.genet.42.110807.091452.

ERBLAND, P. et al. Design and performance of a low-cost, automated, largescale photobioreactor for microalgae production. Aquacultural Engineering, v. 90, p. 102103, 2020. https://doi.org/10.1016/j.aquaeng.2020.102103.

ESCORSIM, A. M. et al. Extraction of Acutodesmus obliquus lipids using a mixture of ethanol and hexane as solvent. Biomass and Bioenergy, v. 108, p. 470-478, 2018. https://doi.org/10.1016/j.biombioe.2017.10.035.

FIERRO, S.; SANCHEZ-SAAVEDRA, M. D. P.; COPALCUA, C. Nitrate and phosphate removal by chitosan immobilized Scenedesmus. Bioresource Technology, v. 99, p. 1274-1279. https://doi.org/10.1016/j.biortech.2007.02.043. 
FINGER, G. S. W. Aumento de biomassa de microalgas cultivadas em fotobiorreatores pela injeção de emissões de grupo motogerador diesel. Dissertação de Mestrado. Curitiba: Universidade Federal do Paraná, 2018.

FRANCO, A. L. C., et al. Biodiesel de microalgas: avanços e desafios. Química Nova. v. 36, n. 3, p. 437-448. 2013. https://doi.org/10.1590/S010040422013000300015.

GHASEMI, Y. et al. Antifungal and antibacterial activity of the microalgae collected from paddy fields of Iran. Journal of Biologial Sciences, 2007.

GINZBERG, A. et al. Chickens fed with biomass of the red microalga Porphyridium sp. have reduced blood cholesterol level and modified fatty acid composition in egg yolk. Journal of Applied Phycology, v. 12, p. 325-330, 2020. https://doi.org/10.1023/A:1008102622276.

GÓMEZ-PÉREZ, C. A. et al. CFD simulation for reduced energy costs in tubular photobioreactors using wall turbulence promoters. Algal Research, v. 12, p. $1-$ 9, 2015. http://dx.doi.org/10.1016/j.algal.2015.07.011.

GONÇALVES, A. L.; SIMÕES, M.; PIRES, J. C. M. The effect of light supply on microalgal growth, $\mathrm{CO}_{2}$ uptake and nutrient removal from wastewater. Energy Conversion and Management, v. 85, p. 530-536, 2014. http://dx.doi.org/10.1016/j.enconman.2014.05.085.

GRIMA, E. M. et al. Recovery of microalgal biomass and metabolites: process options and economics. Biotechnology Advances, v. 20, p. 491-515, 2003. https://doi.org/10.1016/S0734-9750(02)00050-2.

GUERIN, M.; HUNTLEY, M. E.; OLAIZOLA, M. Haematococcus astaxanthin: applications for human health and nutrition. Trends in Biotechnology, v. 21, p. 210-216, 2003. https://doi.org/10.1016/S0167-7799(03)00078-7.

HALIM, F. T. A. Sustainable microalgae-based palm oil mill effluent treatment process with simultaneous biomass production. Canadian Journal of Chemical Engineering, v. 94, p. 1848 - 1854, 2016. 10.1002/cjce.22584.

HENRIQUES, J. D. A. et al. Thermal treatment of clay-based ceramic membranes for microfiltration of Acutodesmus obliquus. Applied Clay Science, v. 150, p. 217-224, 2017. https://doi.org/10.1016/j.clay.2017.09.017. 
HESSE, M. C. S. et al. Optimization of flocculation with tannin-based flocculant in the water reuse and lipidic production for the cultivation of Acutodesmus obliquus. Separation Science and Technology, v. 52, p. 936-942, 2017. https://doi.org/10.1080/01496395.2016.1269130.

HLAVOVA, M. TUROCZY, Z.; BISOVA, K. Improving microalgae for biotechnology-From genetics to synthetic biology. Biotechnology Advances, v. 33, p. 1194 - 1203, 2015. https://doi.org/10.1016/j.biotechadv.2015.01.009.

HUANG, B. et al. Study on high- $\mathrm{CO}_{2}$ tolerant Scenedesmus sp. and its mechanism via comparative transcriptomic analysis. Journal of $\mathrm{CO}_{2}$ Utilization, v. 42, p. 101331, 2020. https://doi.org/10.1016/j.jcou.2020.101331.

HUANG, Y. et al. Comparison of Chlorella vulgaris biomass productivity cultivated in biofilm and suspension from the aspect of light transmission and microalgae affinity to carbon dioxide. Bioresource Technology, v. 222, p. 267-373, 2016. https://doi.org/10.1016/j.biortech.2016.09.099.

JENSEN, G. S.; GINSBERG, D. I.; DRAPEAU, C. Blue-green alga as an immunoenhancer and biomodulador. Journal of the American Nutraceutical Association, v 3, p. 1-7, 2001.

JIANG, Y. et al. Utilization of simulated flue gas for cultivation of Scenedesmus dimorphus. Bioresource Technology, v. 128, p. 359-364, 2013. https://doi.org/10.1016/j.biortech.2012.10.119.

JIMENEZ-PEREZ, M. V. et al. Growth and nutrient removal in free and immobilized planktonic green algae isolated from pig manure. Enzyme and Microbial Technology, v. 34, n. 5, p. 392-398, 2004. https://doi.org/10.1016/j.enzmictec.2003.07.010.

KIM, M. K. et al. Enhanced production of Scenedesmus spp. (green microalgae) using a new medium containing fermented swine wastewater. Bioresource $\begin{array}{llllll}\text { Technology, } & \text { v. } & 98, & \text { p. } & 2220-2228, & 2007 .\end{array}$ https://doi.org/10.1016/j.biortech.2006.08.031.

KOLLER, M.; MUHR, A.; BRAUNEGG, G. Microalgae as versatile cellular factories for valued products. Algal Research, v. 6, p. 52-63, 2014. https://doi.org/10.1016/j.algal.2014.09.002. 
LEE, J-S. et al. Effects of $\mathrm{SO}_{2}$ and $\mathrm{NO}$ on growth of Chlorella sp. KR-1. Bioresource Technology, v. 82, p. 1 - 4, 2002. https://doi.org/10.1016/S09608524(01)00158-4.

LEMOS, J. S. et al. The harvesting of high lipid content microalgae biomass through a flocculation strategy. Revista de Engenharia Térmica, v. 17, p. 4147, 2018. http://dx.doi.org/10.5380/reterm.v17i2.64130.

LEVIN, G. et al. The desert green algae Chlorella ohadii thrives at excessively high light intensities by exceptionally enhancing the mechanisms that protect photosynthesis from photoinhibition. The Plant Journal, v. 106, p. $1260-1277$, 2021. https://doi.org/10.1111/tpj.15232.

LI, X.; XU, H.; WU, Q. Large-scale biodiesel production from microalgae Chlorella protothecoides through heterotrophic cultivation in bioreactors. Biotechnology and Bioengineering, v. 98, p. 764-771, 2007. https://doi.org/10.1002/bit.21489.

LIANG, M-H et al. High-value bioproducts from microalgae: Strategies and progress. Critical Reviews in Food Science and Nutrition, v. 59, p. 2423-2441, 2019. https://doi.org/10.1080/10408398.2018.1455030.

LIANG, Y.; SARKANY, N.; CUI, Y. Biomass and lipid productivities of Chlorella vulgaris under autotrophic, heterotrophic and mixotrophic growth conditions. Biotechnology Letters, v. 31, p. 1043-1049, 2009. https://doi.org/10.1007/s10529-009-9975-7.

LIRIO, F. B. Adição da biomassa da microalga Tetradesmus obliquus em ração canina, com modelagem matemática do processo produtivo e da geração de nutrientes. Tese de Doutorado. Curitiba: Universidade Federal do Paraná, 2019. LIU, J. et al. Production potential of Chlorella zofingienesis as a feedstock for biodiesel. Bioresource Technology, v. 101, p. 8658-8663, 2010. https://doi.org/10.1016/j.biortech.2010.05.082.

LOWREY, J.; YILDIZ, I. Investigation of heterotrophic cultivation potential of Chlorella vulgaris and Tetraselmis chuii in controlled environment wastewater growth media from dairy, poultry and aquaculture industries. Acta Horticulturae, v. 1037, p. 1109-1114, 2014. https://doi.org/10.17660/ActaHortic.2014.1037.147. 
MAEDA, K. et al. $\mathrm{CO}_{2}$ fixation from the flue gas on coal-fired thermal power plant by microalgae. Energy Conversion and Management, v. 36, p. $717-720$, 1995. https://doi.org/10.1016/0196-8904(95)00105-M.

MARQUES, A. E. M. L. et al. Diets containing residual microalgae biomass protect fishes against oxidative stress and DNA damage. Journal of Applied Phycology, v. 31, p. 2933-2940, 2019. https://doi.org/10.1007/s10811-01901825-6.

MARTÍNEZ, M. E. et al. Nitrogen and phosphorus removal from urban wastewater by the microalga Scenedesmus obliquus. Bioresource Technology, v. 73, n. 3, p. 263-272, 2000. https://doi.org/10.1016/S0960-8524(99)00121-2.

MARXEN, K. et al. A photobioreactor system for computer controlled cultivation of microalgae. Journal of Applied Phycology, v. 2005, p. 535-549, 2005. https://doi.org/10.1007/s10811-005-9004-8.

MAZEPA, E. et al. Plant growth biostimulant activity of the green microalga Desmodesmus subspicatus. Algal Research, v. 59, p. 1-10, 2021. http://doi.org/10.1016/j.algal.2021.102434.

MEHARIYA et al. Integrated approach for wastewater treatment and biofuel production in microalgae biorefineries. Energies, v. 14, p. 2282, 2021. https://doi.org/10.3390/en14082282.

MIYAWAKI, B. Purificação de biogás através de cultivo de microalga em resíduos agroindustriais. Dissertação de Mestrado. Curitiba: Universidade Federal do Paraná, 2014.

MIYAWAKI, B. et al. Microalgae derived biomass and bioenergy production enhancement through biogas purification and wastewater treatment. Renewable $\begin{array}{lllll}\text { Energy, } & \text { v. } & 163, & \text { p. }\end{array}$ https://doi.org/10.1016/j.renene.2020.09.045.

MOLINA-CÁRDENAS, C. A.; SÁNCHES-SAAVEDRA, M. P; LIZÁRRAGAPARTIDA. Inhibition of pathogenic Vibrio by the microalgae Isochrysis galbana. Journal of Applied Phycology, v. 26, p. 2347-2355, 2014. https://doi.org/10.1007/s10811-014-0270-1. 
MORAIS, K. C. C. et al. Enhanced microalgae biomass and lipid output for increased biodiesel productivity. Renewable Energy, v. 163, p. 138-145, 2021. https://doi.org/10.1016/j.renene.2020.08.082.

MORENO-GARCIA et al. Microalgae biomass production for a biorefinery system: Recent advances and the way towards sustainability. Renewable and Sustainable Energy Reviews, v. 76, p. 493 - 506, 2017.

MORTENSEN, A.; GEPPEL, A. HPLC-MS analysis of the green food colorant sodium copper chlorophyllin. Innovative Food Science and Emerging Technologies, v. 8, p. 19-25, 2007. https://doi.org/10.1016/j.ifset.2007.03.018.

MULBRY, W. et al. Treatment of dairy manure effluent using freshwater algae: Algal productivity and recovery of manure nutrients using pilot-scale algal turf scrubbers. Bioresource Technology, v. 99, p. 8137-8142, 2008. https://doi.org/10.1016/j.biortech.2008.03.073.

MURTHY, K. N. C. et al. In vivo antioxidant activity of carotenoids from Dunaliella salina - a green microalga. Life Sciences, v. 76, p 1381-1390, 2005. https://doi.org/10.1016/j.lfs.2004.10.015.

NAVARRO, Q. R. et al., Efficient use of biomass and extract of the microalga Desmodesmus subspicatus (Scenedesmaceae) in asymbiotic seed germination and seedling development of the orchid Cattleya warneri. Journal of Applied Phycology, v. 33, p. 2189-2207, 2021. https://doi.org/10.1007/s10811-02102442-y.

NEDBAL, L. et al. A photobioreactor system for precision cultivation of photoautotrophic microorganisms and for high-content analysis of suspension dynamics. Biotechnology and Bioengineering, v. 100, p. 902-910, 2008. https://doi.org/10.1002/bit.21833.

NWOBA, E. G. et al. Light management technologies for increasing algal photobioreactor efficiency. Algal Research, v. 39, p. 101433, 2019. https://doi.org/10.1016/j.algal.2019.101433.

OBAJA, D. et al. Nitrification, denitrification and biological phosphorus removal in piggery wastewater using a sequencing batch reactor. Bioresource 
Technology, v. 87, n. 1, p. 103-111, 2003. https://doi.org/10.1016/S09608524(02)00229-8.

OBAJA, D.; MACÉ, S.; MATA-ALVAREZ, J. Biological nutrient removal by a sequencing batch reactor (SBR) using an internal organic carbon source in digested piggery wastewater. Bioresource Technology, v. 96, p. 7-14, 2005. 10.1016/j.biortech.2004.03.002.

ÖRDÖG, V. et al. Screening microalgae for some potentially useful agricultural and pharmaceutical secondary metabolites. Journal of Applied Phycology, v. 16, n. $\quad 4, \quad$ p. $\quad 309-314, \quad 2004$. https://doi.org/10.1023/B:JAPH.0000047789.34883.aa.

PENG, Y-Y. et al. Simultaneous removal of nutrient and sulfonamides from marine aquaculture wastewater by concentrated and attached cultivation of Chlorella vulgaris in an algal biofilm membrane photobioreactor (BFMPBR). Science of the Total Environment, v. 725, p. 138524, 2020. https://doi.org/10.1016/j.scitotenv.2020.138524.

PULZ, O; GROSS, W. Valuable products from biotechnology of microalgae. Applied Microbiology Biotchnology. v. 65, p. 635-648. 2004. https://doi.org/10.1007/s00253-004-1647-x.

QUEIROZ, M. I. et al. Fish processing wastewater as a platform of the microalgal biorefineries. Biosystems Engineering, v. 115, p. 195-202, 2013. https://doi.org/10.1016/j.biosystemseng.2012.12.013.

RANGLOVÁ, K. et al. Rapid screening test to estimate temperature optima for microalgae growth using photosynthesis activity measurements. Folia Microbiologica, v. 64, p. 615 - 625, 2019.

RAVEN, J. A. Sensing pH?. Plant, Cell \& Environment, v. 13, p. 721-729, 1990. https://doi.org/10.1111/j.1365-3040.1990.tb01086.x.

RIBEIRO, L. L. Robert et al. The experimental validation of a large-scale compact tubular microalgae photobioreactor model. International Journal of Energy Research, v. 41, p. 2221-2235, 2017. https://doi.org/10.1002/er.3784. 
RICHMOND, A. Principles for attaining maximal microalgal productivity in photobioreactors: an overview. In: Asian Pacific Phycology in the 21st Century: Prospects and Challenges. Springer Netherlands, p. 33-37, 2004.

RODAS-ZULUAGA, L. I. et al. Bio-capture and influence of $\mathrm{CO}_{2}$ on the growth rate and biomass composition of the microalgae Botryococcus braunii and Scenedesmus sp. Journal of $\mathbf{C O}_{2}$ Utilization, v. 43, p. 101371, 2021. https://doi.org/10.1016/j.jcou.2020.101371.

SANTOYO, S. et al. Green processes based on the extraction with pressurized fluids to obtain potent antimicrobials from Haematococcus pluvialis microalgae. LWT - Food Science and Technology, v. 42, n. 7, p. 1213-1218, 2009. https://doi.org/10.1016/j.lwt.2009.01.012.

SATYANARAYANA, G. Kestur; MARIANO, B. André, VARGAS, V. C. José. A review on microalgae, a versatile source for sustainable energy and materials. International Journal of Energy Research, v. 35, p. 291-311, 2011. https://doi.org/10.1002/er.1695.

SCHERER, D. Marisa et al. Environmental evaluation of flocculation efficiency in the separation of the microalgal biomass of Scenedesmus sp. cultivated in fullscale photobioreactors. Journal of Environmental Science and Health, v. 53, p 1-8, 2018. https://doi.org/10.1080/10934529.2018.1470961.

SCHERER, D. Marisa et al. Environmental study of producing microalgal biomass and bioremediation of cattle manure effluents by microalgae cultivation. Clean Technologies and Environmental Policy, v. 19, p. 1745-1759. https://doi.org/10.1007/s10098-017-1361-x.

SCHROEDER, Luiza et al. Energy analysis of lipid extraction of Scenedesmus sp. produced in pilot scale. Revista de Engenharia Térmica, v. 4, p. 22-33, 2015. http://dx.doi.org/10.5380/reterm.v14i1.62110.

SELESU, F. H. Nelson et al. Maximum microalgae biomass harvesting via flocculation in large scale photobioreactor cultivation. The Canadian Journal of

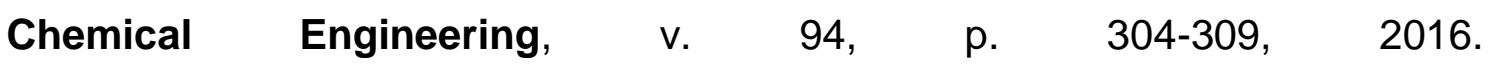
https://doi.org/10.1002/cjce.22391. 
SILVA, G. Angela et al. Life cycle assessment of biomass production in microalgae compact photobioreactors. Global Change Biology-Bioenergy, v. 7, p. 184-194, 2015. https://doi.org/10.1111/gcbb.12120.

SINGH, H. M. Bio-fixation of flue gas from thermal power plants with algal biomass: Overview and research perspectives. Journal of Environmental $\begin{array}{lllllll}\text { Management, } & \text { v. } & 245, \quad \text { p. } & 519 \quad \text { - } & 539,\end{array}$ https://doi.org/10.1016/j.jenvman.2019.01.043.

SPOLAORE, P. et al. A. Commercial applications of microalgae: review. Journal of Bioscience and Bioengineering, v. 101, p. 87-96, 2006. https://doi.org/10.1263/jbb.101.87

SUALI, E.; SARBATLY, R. Conversion of microalgae to biofuel. Renewable and Sustainable Energy Reviews, v. 16, p. 4316-4342, 2012. https://doi.org/10.1016/j.rser.2012.03.047

SUGAI-GUÉRIOS, $\mathrm{H}$. Maura et al. Mathematical model of the $\mathrm{CO}_{2}$ solubilization reaction rates developed for the study of photobioreactors. The Canadian Journal of Chemical Engineering, v. 92, p. 787-795, 2014. https://doi.org/10.1002/cjce.21937.

SUN, Y. et al. Optimizing light distributions in a membrane photobioreactor via optical fibers to enhance $\mathrm{CO}_{2}$ photobiochemical conversion by a Scenedesmus obliquus biofilm. Industrial and Engineering Chemestry Research, v. 59, p. 21654-21662, 2020. https://doi.org/10.1021/acs.iecr.0c03854.

STODDARD, M. C. Mimicry and masquerade from the avian visual perspective. Current Zoology, v. 58, p. $630 \quad$ - $\quad 648, \quad 2012$. https://doi.org/10.1093/czoolo/58.4.630.

TAHER. D. M., Biodiesel de microalgas cultivadas em dejeto suíno biodigerido. Dissertação de Mestrado. Curitiba: Universidade Federal do Paraná, 2013.

TAIZ, L.; ZEIGER, E. Fisiologia Vegetal. Editora Artmed. 3a edição. Porto Alegre, 2006.

TANG, $H$. et al. Continuous microalgae cultivation in a photobioreactor. Biotechnology and Bioengineering, v. 109, p. 2468-2474, 2012. https://doi.org/10.1002/bit.24516. 
TASTAN, B. E. et al. Utilization of LGP and gasoline engine exhaust emissions by microalgae. Journal of Hazardous Materials, v. 246-247, p. 173-180, 2013. https://doi.org/10.1016/j.jhazmat.2012.11.035.

TELLES, C. Enio et al. A genset and mini-photobioreactor association for $\mathrm{CO}_{2}$ capturing, enhanced microalgae growth and multigeneration. Renewable Energy, v. 125, p. 985-994, 2018. https://doi.org/10.1016/j.renene.2018.03.027. THOMPSON, P. A. GUO, M. HARRISON, P. J. Effects of variation in temperature: on the biochemical composition of eight species of marine phytoplankton. Journal of Phycology, v. 28, p. 481-488, 1992. https://doi.org/10.1111/j.0022-3646.1992.00481.x.

TREDICI, M. R. Mass production of microalgae: photobioreactors. In: RICHMOND, A. Handbook of Microalgal Culture: Biotechnology and Applied Phycology. Blackwell Science, 2004. p. 178-214.

UDUMAN, N.; QI, Y.; DANQUAH, M. K. Marine microalgae flocculation and focused beam reflectance measurement. Chemical Engineering Journal, v. 162, p. 935-940, 2010. http://dx.doi.org/10.1016/j.cej.2010.06.046.

UGWU, C. U.; AOYAGI, H.; UCHIYAMA, H. Photobioreactors for mass cultivation of algae. Bioresource Technology, v. 99, p. 4021 - 4028, 2008. https://doi.org/10.1016/j.biortech.2007.01.046.

VARGAS, V. C. José et al. Mass transfer modeling and maximization of hydrogen rhythmic production from genetically modified microalgae biomass. International Journal of Heat and Mass Transfer, v. 101, p. 1-9, 2016. https://doi.org/10.1016/j.ijheatmasstransfer.2016.04.117.

VARGAS, V. C. José et al. Modeling microalgae derived hydrogen production enhancement via genetic modification. International Journal of Hydrogen $\begin{array}{lllll}\text { Energy, } & \text { v. } & 41, & \text { p. } & \text { 8101-8110, }\end{array}$ https://doi.org/10.1016/j.ijhydene.2015.12.217.

VARGAS, V. C. José et al. The microalgae derived hydrogen process in compact photobioreactors. International Journal of Hydrogen Energy, v. 39, p. 95889598, 2014. https://doi.org/10.1016/j.ijhydene.2014.04.093. 
WANG, B. et al. $\mathrm{CO}_{2}$ bio-mitigation using microalgae. Applied Microbiology Biotechnology, v. 79, p. 707 - 7018, 2008. DOI 10.1007/s00253-008-1518-y. WANG, H. et al. The contamination and control of biological pollutants in mass cultivation of microalgae. Bioresource Technology, v. 128, p. 745 - 750, 2013. https://doi.org/10.1016/j.biortech.2012.10.158.

WANG, H-Y.; BLUCK, D.; VAN WIE, B. J. Conversion of microalgae to jet fuel: Process design and simulation. Bioresource Technology, v. 167, p. 349-357, 2014. https://doi.org/10.1016/j.biortech.2014.05.092.

WANG, J-H. et al. Microalgal attachment and attached systems for biomass production and wastewater treatment. Renewable and Sustainable Energy Reviews, v. 92, p. 331-342, 2018. https://doi.org/10.1016/j.rser.2018.04.081.

XIAOGANG, H. et al., Microalgal growth coupled with wastewater treatment in open and closed systems for advanced biofuel generation. Biomass Conversion and Biorefinary, 2020. https://doi.org/10.1007/s13399-020-01061w.

XU, H.; MIAO, X.; WU, Q. High quality biodiesel production from a microalga Chlorella protothecoides by heterotrophic growth in fermenters. Journal of $\begin{array}{lllll}\text { Biotechnology, } & \text { v. } & 126, & \text { p. } & 499-507,\end{array}$ https://doi.org/10.1016/j.jbiotec.2006.05.002.

YANG, C.; HUA, Q.; SHIMIZU, K. Energetics and carbon metabolism during growth of microalgal cells under photoautotrophic, mixotrophic and cyclic lightautotrophic/dark-heterotrophic conditions. Biochemical Engineering Journal, v. 6, p. 87-102, 2000. https://doi.org/10.1016/s1369-703x(00)00080-2.

YADAVALLI, R.; HEGGERS, G. R. V. N. Two stage treatment of dairy effluent using immobilized Chlorella pyrenoidosa. Journal of Environmental Health Science and Engineering, v. 11, 2013.

YANG, J. et al. Experimental study on microalgae cultivation in novel photobioreactor of concentric double tubes with aeration pores along tube length direction.

International Journal of Green Energy, v. 14, p. 1269 - 1276, 2017. https://doi.org/10.1080/ 15435075.2017.1402772. 
ZERIOUH, O. et al. Biofouling in photobioreactors for marine microalgae. Critical Reviews in Biotechnology, v. 37, p. 1006-1023, 2017. https://doi.org/10.1080/07388551.2017.1299681.

ZHAO, B.; SU, Y. Process effect of microalgal-carbon dioxide fixation and biomass production: a review. Renewable and Sustainable Energy Reviews. v. 31, p. 121-132. 2014. https://doi.org/10.1016/j.rser.2013.11.054.

ZIMMERMAN, W. B. et al. Design of an airlift loop bioreactor and pilot scales studies with fluidic oscillator induced microbubbles for growth of a microalgae Dunaliella salina. Applied Energy, v. 88, p. 3357 - 3369, 2011. 10.1016/j.apenergy.2011.02.013.

\section{Autores}

Beatriz Santos ${ }^{1}$, Diego de Oliveira Corrêa ${ }^{1, *}$, Nelson Fernando Herculano Selesu², Vanessa Merlo Kava ${ }^{3}$, André Bellin Mariano ${ }^{4}$, José Viriato Coelho Vargas $^{5}$

1. Núcleo de Pesquisa e Desenvolvimento de Energia Autossustentável, Universidade Federal do Paraná, Av. Cel. Heráclito dos Santos, CEP 81531 980, Curitiba, Brasil.

2. Departamento de Engenharia de Bioprocessos e Biotecnologia, Universidade Federal do Paraná, Av. Cel. Heráclito dos Santos, CEP 81531 980, Curitiba, Brasil.

3. Departamento de Genética, Universidade Federal do Paraná, Av. Cel. Heráclito dos Santos, CEP 81531-980, Curitiba, Brasil.

4. Departamento de Engenharia Elétrica, Universidade Federal do Paraná, Av. Cel. Heráclito dos Santos, CEP 81531-980, Curitiba, Brasil.

5. Departamento de Engenharia Mecânica, Universidade Federal do Paraná, Av. Cel. Heráclito dos Santos, CEP 81531-980, Curitiba, Brasil.

*Autor para correspondência: diego.biodoc@gmail.com 